\title{
Exploration and Practice on the Construction of Excellent Resource Sharing Course in Higher Vocational: Inverter Touch Screen Application Technology
}

\author{
$\mathrm{Li} \mathrm{Li}$ \\ Binzhou Polytechnic \\ Binzhou, China
}

\author{
Qian Lv \\ Binzhou Polytechnic \\ Binzhou, China
}

\author{
Yanyan Cao \\ Binzhou Polytechnic \\ Binzhou, China
}

\begin{abstract}
Combined with the National Excellent Resource Sharing Course Construction Project of the Ministry of Education, taking the construction of the inverter touch screen application technology course as an example, the paper explores the construction of the curriculum system based on the position competency. From the aspects of curriculum system design, construction ideas, curriculum content, teaching mode and implementation conditions, this paper discusses the construction of quality resource sharing courses, builds fragmented teaching resources to meet the needs of users, and provides reference for improving the construction of national quality resources sharing courses.
\end{abstract}

Keywords-higher vocational school; inverter touch screen application technology; resource sharing course; practice; teaching reform

\section{INTRODUCTION}

The excellent resource sharing course is a national higher vocational education quality engineering project needs to follow the changes in the international higher education era. The project aims to promote the transformation of education and teaching concepts, lead the reform of teaching content and teaching methods, and promote the construction of highquality curriculum teaching resources in higher vocational schools through modern information technology means, improve the quality of personnel training, and serve the construction of a learning society [1-2].

At present, the atmosphere of classroom teaching in many universities is not good, as there are many students busy on their smartphones, so the quality of university teaching is worrying. In 2015, China Youth Daily reported that college teachers are in a dilemma, that is, if they are strict on students, they will be scolded by students; if they just sit by and do nothing, they will lose the moral conscience of teachers. At the same time, it is difficult for local college students who are not highly independent in learning to maintain the motivation of learning in the absence of teacher monitoring. In addition, the questions encountered by students in self-learning cannot be timely answered, affecting the enthusiasm and autonomy of learning. Given this, students may give up halfway. In view of the above problems, combined with the advantages of the network teaching platform and the "online + offline" flipped classroom teaching mode, it is necessary to build and share high quality teaching resources with modern information technology means.

\section{COURSE SYSTEM DESIGN IDEAS}

\section{A. General ideas}

The "Inverter Touch Screen Application Technology" course is a professional core competence course for mechatronics technology majors in higher vocational colleges. This course is a school-enterprise co-construction course. Experts from enterprise are employed to participate in the formulation of professional talent training programs, reconstructed the curriculum system, and conduct professional analysis based on the electromechanical maintenance posts through discussions and argumentations. The professional ability analysis, content reconstruction, project selection, teaching goal evaluation, etc. are all completed by the fulltime teacher and part-time teachers. The teaching of this course is centered on cultivating students' practical ability by setting up training programs, and repeatedly training the design, installation and debugging of frequency converters and touch screens. According to the design, installation and commissioning work process of the frequency converter and the touch screen, the teaching is carried out in turn, and the final purpose of cultivating vocational skills and professional accomplishment is achieved when tasks are completed.

\section{B. Course System Construction Ideas}

Take the mechatronics technology as an example, as shown in Fig.1, the course group discussed and analyzed that 
the initial position of the major is the mechanical and electrical equipment maintenance; the higher positions are the intelligent maintenance and repair of the intelligent electromechanical system, the operation and maintenance of the intelligent production line, and the technical management position. Reorganize and optimize the teaching content which can be adapted to positions like the maintenance of mechanical and electrical equipment, the adjustment and maintenance of intelligent electromechanical systems, the intelligent production line installation and maintenance, and the professional qualification assessment outline. Realize the integration of theoretical teaching and practical teaching. Establish a pre-class, in-class, and after-school assessment system for the whole process, and set up reasonable expanded knowledge.

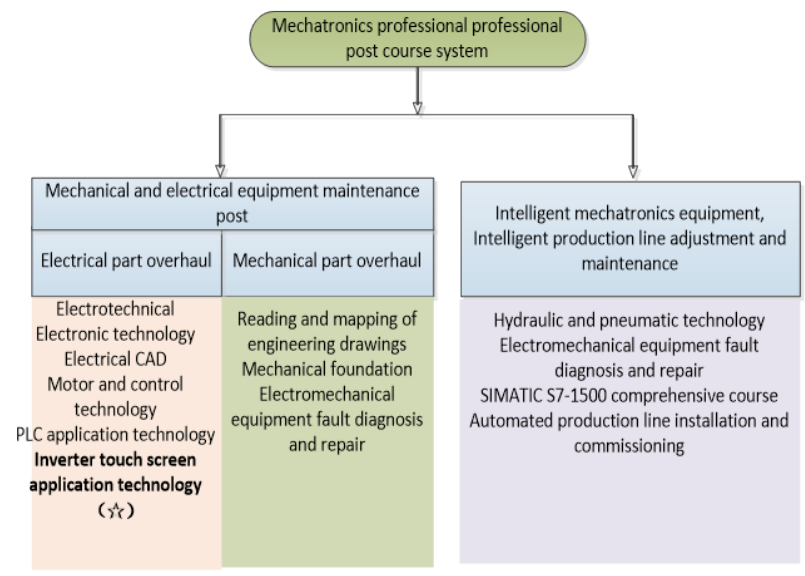

Fig. 1. Block diagram of the mechanical and electrical professional career course system

The curriculum system based on the post ability is a professional core competence training course. That one can ,according to the requirements of the production, set the parameter and program of the inverter, touch screen, stepping and servo drive equipment is the training purpose of the course.

\section{Optimization of course content}

The course team takes the mechanical equipment maintenance position as the main line and combines the national vocational qualification evaluation standards. The enterprise experts and professional teachers analyze, sequence, classify and select the positions of mechanical equipment maintenance. Three contents are selected as 8 teaching modules which contain 30 tasks as shown in Fig.2. As the electromechanical equipment used by students in the enterprise vary, typical, representative and versatile tasks under each module are selected. The design of each task comes from the real working process of the enterprise mechanical equipment maintenance position, ensuring that the learning process and work process, learning tasks and work tasks, school assessment and career evaluation are consistent.

According to the responsibilities and work process of the position of the enterprise, combined with the law of student cognitive development, the teaching content is designed according to the principle of "cognitive law from sensibility to rationality, skill operation from simple to complex, and control system from single to comprehensive”. The teaching design breaks the simple sub-section of this traditional subject knowledge system, sorts out the content that is not highly correlated with job skills, and dilute the systemic and integrity of knowledge. The corresponding knowledge points are drawn from the needs of typical work processes and tasks to achieve a complete integration of knowledge and skills. Through integration and ordering, the teaching content is gradually advanced step by step, so that students gradually improve their professional ability and professional quality in the learning process.

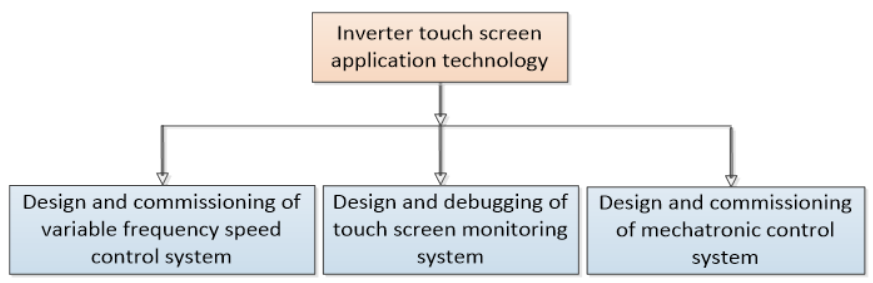

Fig. 2. Typical teaching project

\section{DISCUSSION ON THE "ONLINE + OFFLINE" FLIPPING CLASSROOM TEACHING MODE}

The online and offline teaching mode (Fig. 3) integrates the "offline" (face-to-face teaching) teaching with "online" (network teaching) teaching by conducting classroom teaching with information technology. Teachers and students, students and students can carry out learning activities and deep interactive exploration. In the classroom, the teacher guides the students to actively think and help each other. After class, the students independently arrange the "online" self-study according to their own habits of interest, and complete the learning tasks arranged by the teachers, so as to cultivate the ability to learn actively. The teaching process has been transformed from the completion of teaching tasks emphasized to the internalization and absorption of knowledge highlighted, achieving the goal of "teacher talk less, students learn more" [3-6].

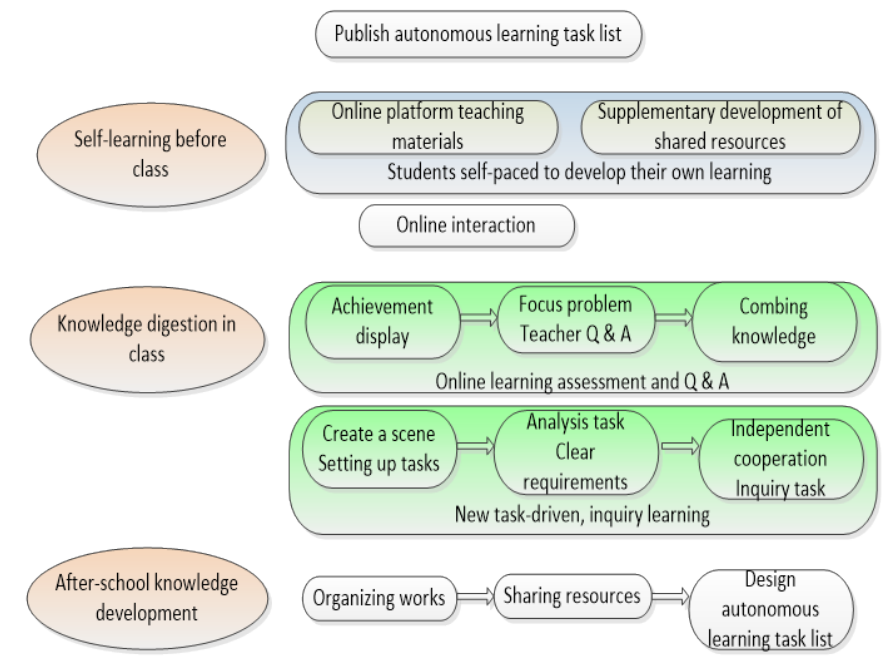

Fig. 3. Online and offline hybrid teaching mode 
The course consists of 3 teaching modules, a total of 8 projects. Each teaching module adopts project-based flip classroom teaching mode. According to the basic processes of "basic cognition- internalization-integrated application". The six links of task learning, namely, accepting tasks - planning decision making - implementation - checking - evaluating (summarizing and improving) are integrated into the flipped classroom learning. Make students truly become the initiative of knowledge acquisition, teachers become the guide of knowledge transfer, improve the learning and application of students' knowledge.

\section{A. Basic cognitive stage}

Conducted independent learning before class. Teachers assign tasks to students through the teaching curriculum resource platform. Students can freely choose when, where and with what kinds of equipment to learn independently according to the task prompts. They can log in to the course resource platform, download learning resources, watch videos and study cases, complete the relevant task learning in the project, and submit the task work. The teacher collects and organizes the task work submitted by the students before class, collects the common mistakes, and summarizes the errorprone points and knowledge points.

\section{B. Internalization phase}

The teacher will give a detailed explanation of the difficulty and skill in the task, then formulate the sub-task, organize the students to discuss in groups, and perform task representation within the class and make detailed comments. According to the guidance provided by the teacher, the students improve the project implementation plan, complete the project under the condition of complete equipment, and complete the operation and debugging under the supervision of the teacher. The teacher tracks the situation in real time, records the operation, and reminds students of the safety operation specification, so that the students can complete the project task smoothly and autonomously while ensuring their own safety.

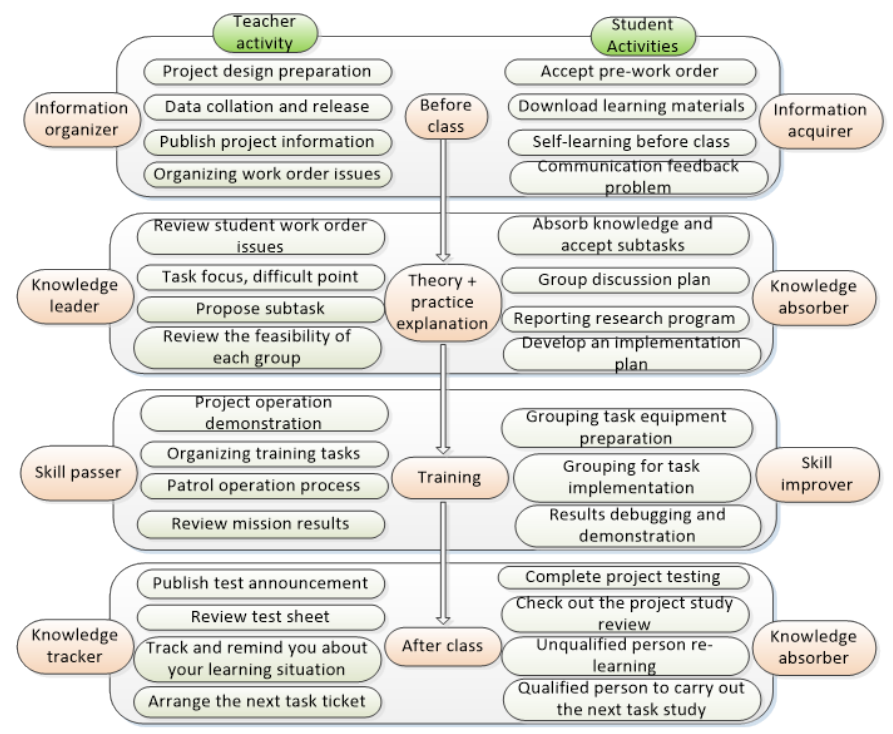

Fig. 4. Inverter touch screen application technology course teaching mode

\section{Comprehensive application}

Students use the theoretical knowledge and operational skills they have learned to solve the problems encountered in the extended case. Teachers refer to the professional qualification evaluation criteria and evaluate the implementation.

Through the above teaching mode, students can master the frequency converter and touch screen, master the comprehensive debugging of their software and hardware. Students learn in the operation, gradually understand the programming ideas, master the correct programming skills and methods, while cultivating practical ability. That will gradually train students' self-learning ability and further cultivate students' innovative spirit. The project-driven flipped classroom teaching mode highlights the cultivation of professional ability, combines practical teaching and enterprise project development, trains students' project development ability, and improves students' learning ability and innovation ability. The teaching implementation process is shown in Fig.4.

\section{TEACHING CONDITIONS}

\section{A. Building an information platform to optimize curriculum resources and innovative teaching methods}

The predecessor course "PLC and Inverter Application Technology" of "Inverter Touch Screen Application Technology" was recognized as the Shandong Provincial Quality Course in December 2011. The course website has been completed (website: http://10.10.0.19). In order to facilitate more learners to learn online and make up for the shortcomings of the online interactive of the course website, the course group utilizes the features of online interaction and real-time response in a large-scale online open platform, and in large-scale open teaching in September 2016 to create the online open course like "PLC and Inverter Application Technology" and "Inverter Touch Screen Application Technology". Students can learn, answer questions, discuss, evaluate, etc. in real time through mobile devices such as mobile phones and IPAD. At the same time, they can use the Blue Ink Cloud Class APP to implement classroom sign-in, cloud textbook learning, resource browsing, brainstorming, Q\&A testing, and group discussion and other comprehensive teaching activities. It has realized the online and offline learning, class and after-school interaction. The actionoriented teaching model integrating the "teaching, learning, doing, evaluation" has greatly improved the students' enthusiasm for learning and received good teaching results.

\section{B. School-enterprise cooperation, apprenticeship training}

the College, China Wanda Group and Weiqiao Aluminium and Jingbo Holdings jointly established the Binzhou Modern Apprenticeship Pilot Cooperation Alliance. Signed a cooperation agreement, integrated corporate culture requirements, developed a personalized talent training program, and defined the responsibilities, rights and obligations, cost sharing, implemented the "school enterprise alliance, integrated education, alternating learning and training, and talents in positions " modern apprenticeship pilot. The 
implementation of "school-enterprise integration, teachermaster integration, student-apprentice integration, classroompost integration" education enables students improve technical skills in the "learning, training, internship" cycle, promotes the status change from student, apprentice, quasi-employee, to employee, and cultivates innovative, developmental, and composite technical talents that meet the requirements of enterprise positions.

\section{Construction of training base}

Relying on the first "Shandong Province Vocational Education Public Training Base" set up in the college, Shandong Province Quality School Construction Key Professional Mechatronics Technology Professional Group and Shandong Province Higher Vocational Education Highlevel Key Construction High-end Aluminum Product Processing Professional Group, the school join hands with enterprise to build the mechatronics technology training room, automated production line training room and Siemens advanced automation technology skills research center which are designed in line with the requirements of the post like the maintenance of mechanical and electrical equipment, intelligent mechanical and electrical systems, maintenance and repair, intelligent production line installation and maintenance. At present, the training base is at the leading level among similar vocational colleges in the country. The college has also cooperated with more than 20 companies including China Wanda Group, Weiqiao Aluminium and Jingbo Holdings to establish a long-term and stable off-campus training base.

In recent years, during the construction of key professional mechatronics technology in Shandong Province, the school has invested more than 5.6 million Yuan to purchase advanced teaching equipment such as intelligent control basic training platform and small industry 4.0MPS system. The enterprise Siemens has invested more than 1.5 million Yuan to purchase the intelligent control basic training platform, the intelligent control advanced application platform, and the industrial robot comprehensive training device. The training conditions in the school is the best in the whole country.

\section{CONCLUSION}

\section{A. Characteristics of the course resources}

1) Resources focus on granulation during the development process. In the development process, the course team selects the projects around the electromechanical positions, designs the task and the resources according to the work process of the electrical maintenance and mechanical maintenance.

2) Resources are systematically sorted. This course closely focuses on the needs of mechanical and electrical equipment maintenance positions, that is, it conforms to the order of use of equipment, and is in line with the cognitive law of students. The overall design of the course is from simple to complex, from single to comprehensive, achieving a systematic process based on the mechanical and electrical equipment maintenance position.

3) Resources focus on user needs during use. The resources meet the requirements of students, social trainees, and enterprise personnel to learn the tasks of mechanical and electrical equipment maintenance positions and make it easier for different learners to find the smallest knowledge points and skill points. Resources can be gained faster, easier and more convenient. Extended resources encompass continuing education resources such as Siemens International Certification, mechanical and electrical equipment maintenance, mechanical and electrical safety and other related materials, professional job standard training and knowledge update training, and corporate cases, famous forums and related website links.

\section{B. Innovations in this course}

This course builds a curriculum system based on the ability of the post, combined with the national vocational qualification assessment criteria. The enterprise experts and professional teachers work together to analyze, order, classify and select the positions of mechanical equipment maintenance. The practices of "online + offline" flipping classroom teaching mode are explored. A modern apprenticeship pilot program of "school enterprise alliance, integrated education, alternating learning and training, and talents in positions” is carried out for education.

\section{REFERENCES}

[1] ZHANG You-jun, JIN Jia-qi and SUN Xin-wei, "Construction and application of provincial-level quality course teaching resource," JOURNAL OF MACHINE DESIGN. Chinese, Vol.35 S2, pp. 419-422, Jul 2018.

[2] HOU Yong, "Researching and practice of typical weld joint SMAW implementation excellent resource in the higher vocational college," Electric Welding Machine. Chinese, Vol.44 No.8 , pp.6-10, Aug 2014.

[3] Johnson and Don.H, "Teaching a MOOC Experiences from the frontline,” IEEE Digital Signal Processing and Signal Processing Education Meeting(DSP/SPE). Napa, California, USA, pp. 268-272, August 2013.

[4] Piedra N and Chicaiza J, "CCW-S: enablers for building sustainable Open Education,”2013IEEE Global Engineering Education Conference. Berlin, Germany, pp. 1262-1271, March 2013.

[5] Kay J, Reimann P and Diebold E, "MOOCs: So Many Learners, So Much Potential, Intelligent Systems,” IEEE, USA, Vol.28. pp.70-77, June 2013.

[6] R. Gluga, T. Lever, and J. Kay, "Foundations for Modeling University Curricula in Terms of Multiple Learning Goal Set," IEEE Trans. Learning Technologies, USA , vol. 6, pp. 25-37, January 2013. 